\title{
Strategy Selection of Multi-Subjects Collaboration in Grass-Roots Society Governance: A Case Study Based on Project of Children's Sunshine Holiday House in Huzhou, Zhejiang
}

\author{
Langzi CHEN* \\ Nanjing Forest Police College \\ Email: langzi_chen@hotmail.com \\ ${ }^{*}$ Corresponding author
}

Keywords: grass-roots society governance, joint collaboration, multiple subjects, strategy selection

\begin{abstract}
The practice of participating in juvenile safety education and crime prevention, promoted by multiple subjects such as grass-roots public security organs, college and university voluntary associations, primary and junior schools and enterprises, is an active exploration and interpretation of social governance in the new era. It has established a good communication and interaction platform between public security organs and juvenile and their families, which promotes the harmonious police-civilian relations, and diversifies the channels for solving social conflicts in the grassroots society. However, some resource-based development difficulties may occur during its development process. There is a case analysis of project of Children's Sunshine Holiday House in Huzhou, Zhejiang, which is helpful to seek a solution how to break through the difficulties and obtain opportunities for sustainable development under new guiding concept of Mutual Building and Sharing and Governance, so as to provide reference for the development of other similar projects.
\end{abstract}

\section{Introduction}

It is the inherent demand of the national governance system modernization and the national governance capacity modernization that the whole society should be full of vitality while it is in stability. In the system of national governance, society is both a subject and an object. As a subject, society is an important supporting force for joint participation in state governance. As an object, society is an important sector to be governed by thestate. More attentions must be paid to how to optimize the social governance based on the ever-changing social structure and the inherent needs of state governance.

In the Third Plenary Session of the 18th Central Committee of the Communist Party of China, the Decision of the Central Committee of the Communist Party of China on Some Major Issues Concerning Comprehensively Deepening the Reform is adopted by this congress. The concept of Social Governance is put forward in the form of an official document for the first time, which explicitly proposed that we need to innovate the social governance system and improve the standards of social governance. The19th session of national congress of the communist party of China explicitly proposed that a social governance pattern of Mutual Building and Sharing and Governance should be established; meanwhile, it also proposed that we need to carry out the system construction of social governance, to improve the levels of four modernization (industrialization, informatization, urbanization and agricultural modernization)[1], and to strengthen the construction of four systems[1]( QMS, EMS, HACCP,OHSMS). In the 4th Plenary Session of the 18th Central Committee of the Communist Party of China, the Key CPC session adopted a Decision on Some Major Issues Concerning How to Uphold and Improve the System of Socialism with Chinese Characteristics and Advance the Modernization of China's System and Capacity for Governance, which is a major strategic task of the Communist Party of China and has a further clarification for the task of the modernization of national governance system and national governance capacity. 
Under the new concepts of social governance concepts of the CPC and the state, the administrative system reform and the transformation of government functions in the political domain, the marketoriented reform in the economic domain, the pluralistic governance in the social domain, and the standardized development of social organizations or groups, these changes have formed a new momentum of social development and governance. At the same time, the changes also demonstrate the transitions in political power, economic power and social power structure and the formation of subjects in pluralistic social governance.

The grass-roots public security organs, collaborated with university volunteer associations, primary and junior schools and enterprises in Huzhou City, Zhejiang Province, are devoted to actively exploring innovative models for participating in social governance. They create the project of Children's Sunshine Holiday House. The project is a practice based on an active policing model by grass-roots public security organs, participating in the youth education process, actively exploring innovative solutions to prevent and deal with misconducts, wrong behaviors, and crimes of adolescents. Meanwhile, it is also an active exploration and interpretation of social governance in the new era. It has established a good communication and interaction platform between public security organs and juvenile and their families, which promotes the harmonious police-civilian relations, and diversifies the channels for solving social conflicts in the grassroots society. It is a new measure to inherit and carry forward the Fengqiao Experience. By the analysis of the collaboration model of this project, this paper is trying to present a complete picture of resource dilemma faced by the police subject in participating in grassroots social governance, and is trying to find a way to break through the difficulties and obtain opportunities for sustainable development under new guiding concept of Mutual Building and Sharing and Governance, to provide reference for the development of other similar projects.

\section{Resource Dilemma Faced by Police Subject in Project of Children's Sunshine Holiday House}

In July 2012, the Luoshizhuang Police Office where the second-level heroic model of the Ministry of Public Security and the community policeman, Mr. Ma Changlin works there, collaborated with student volunteer associations from Huzhou Vocational and Technical College, Huzhou University, Renhuangshan Primary School and social companies, established the Children's Sunshine Holiday House project. Over the years, the project focuses on building activity classrooms and other places. It has provided educational development services about academic advising, life safety, discipline and physical fitness, teamwork and police camp cultural experience for nearly 4,000 kids of new residents in the area of the police office.

In general, the initial purpose of juvenile education services provided by polices in various countries is to build a positive interaction relationship between police and young people, to change negative attitudes between them, thereby to strengthen effect on preventing and dealing with misconducts, wrong behaviors, and crimes of adolescent. For example, the project of Drug Abuse Resistance Education (DARE), the project of Gang Resistance Education and Training (G.R.E.A.T.) [3] of US Police, and the project Safety Network Project in Schools of Macau Judicial Police.

The project of Children's Sunshine Holiday House is located at the rural-urban fringe zone of Luoshizhuang Community, covering less than $2 \%$ of Longxi Street. However, the crime cases account for $35 \%-38 \%$ in the whole street, which is a typical area of security disorder. The community has a migrant population of more than 18,000 and a local population of less than 2,000. The migrant population accounts for more than $90 \%$ of the total population. The situation of migrant population is complex, involving 26 provinces and 18 ethnic groups. It is extremely prone to provocations and even gathering fights, which makes the social governance there more difficult. In the spare time, most of the children of these new residents are left unattended, leading to a large amount of potential safety 
hazards. In addition, adolescents are featured with poor capability in self-regulation of emotion, and they are more vulnerable to influence from the external society and pressure from their peer, and they are unable to assess long-term consequences. In such an environment, it is more prone to misconducts, wrong behaviors, and even crimes of adolescents [4].

Based on the problem-oriented community policing model, policemen in Luoshizhuang Police Office begin to understand their work from a new perspective. The scope of the policeman's work is no longer limited to the investigation and punishment of illegal crimes, but includes a series of measures to deal with problems that endanger the safety of the community [5]. The basic work idea is changed to analyze the hidden reasons behind several illegal crimes and find out methods and measures to reduce or eliminate a certain type of illegal crimes fundamentally. This policing mode has strong similarities with the Fengqiao Experience. It requires grass-roots public security organs to actively participate in crime prevention and crackdown of illegal crime in its seed stage on the basis of harmonious police-civilian relations. Therefore, it is an inevitable choice for the police to actively participate in the education and services of juvenile

However, there are only 2 policemen and 4 auxiliary policemen in the Luoshizhuang Police Office. The human resources to be invested in this project is not enough. The funding support is also insufficient. There is a resource dilemma of Congenital Inadequacy and Acquired Deficiency. On the one hand, the structural space for its resource sources is narrow. Compared to the crackdown-oriented actions of public security organs, preventive projects can obtain less funding resources and the implementations of those preventive projects are relatively delayed. On the other hand, the there is a single channel for resource acquisition, so a strong one-way dependence on external resources is easily formed, which weakens the defense ability to confront with the external risk environment. More seriously, it may lead to replacement of superior leaders or retirement of backbone of project. It's hard for the project to have a continuous development. In the development process of Children's Sunshine Holiday House project, it actively faces many of the above-mentioned resource predicaments, and combines the resource advantages among different subjects. Finally, the project has reached and established interactions and cooperation with multi-subjects such as college and university volunteer associations, compulsory education schools and enterprises.

\section{Practical Strategy of Multi-Subjects Collaboration of Project}

The Children's Sunshine Holiday House project, led by grass-roots public security organs as a general crime prevention project and educational service project, differs greatly from the development philosophy, operating logic and management model of other subjects such as education departments, social organizations and enterprises. It is this difference that creates the necessity and possibility of cooperation, in order to achieve the complementary advantages and resource integration among different subjects, and in order to build a social support network and effective social capital for the project. The practical strategy of multiple subjects' collaboration is undergoing changes and adjustments along with the development ideas of the project. During the project, the strategy's own professional service capabilities are increased, thus vividly showing the dynamic characteristics of cross-border cooperation strategy in different development stages of the project [6].

\subsection{Individual participation of volunteers in association construction}

Colleges and universities possess abundant knowledge and technical resources, and they have certain knowledge authority in the government and society. At the same time, scholars in colleges and universities have responsibility to provide intellectual interpretation and analysis of social issues related to the development of society [7]. Students in colleges and universities have advantages of active thinking ability, abundant mental creativity and superb knowledge storage. Grass-roots public security organs should make the most of these advantages to make them become important supporting forces for development of project. At the beginning of the Children's Sunshine Holiday House project, 
some university volunteers and social volunteers are responsible for the daily teaching and management work. This participation method mainly depends on individual volunteers, which reliefs the situation of shortage of staff to a certain extent. However, the population shift is serious, namely, some only come once or twice, and some have a sudden stop after teaching for a period. Therefore, the whole organization activity is lack of coherence and continuity. In August 2017, the State Council issued the Regulation of Volunteer Service to further encourage college students to participate in voluntary activities and to cultivate voluntary dedication spirit, which provides system guarantee to attract more university volunteers to join in cooperation with universities.

The volunteer support system of the project mainly consists of youth volunteers represented by college and university students and community security volunteers. Regarding the university volunteer team, the public security organs and volunteer representatives jointly formulates a more detailed Administrative Manual for those volunteers, and specific requirements and regulations are presented for admission of volunteers, recruitment and training of volunteers, establishment and development of teams, and management of volunteer teams and other provisions, and it also clearly defined the management structure of volunteer teams, so a comprehensive volunteer management system has been initially constructed, which has provided a strong backing support for the standardized development of association's activities. At the same time, a reward system and incentive mechanism for volunteer is performed, such as holding periodic meetings for commendation and encouragement, giving recognition to effectiveness of excellent volunteer teams, which facilitates to stimulate volunteers' inner passion and cultivate their recognition of police culture and team belonging, and which is active to guide volunteers to provide professional volunteer services.

\subsection{Changes in basic models of school-police joint education}

The original idea of the school-police joint education by Luoshizhuang Police Office and Renhuangshan Primary School was born around 2003. Its background is based on the activity of To Be A Part-Time Legal Deputy Principal. It is needed to select some outstanding community policemen from the public security organs. According to requirements of compulsory education, those selected people are appointed to teach specific courses about safety education in schools under stage of compulsory education stage [8], which is regarded as an integral part of school safety education. On this basis, the Children's Sunshine Holiday House project has depended this two-sides cooperation education model. The cooperation has gone through the alliance model of extramural resources, the alliance model of extramural curriculum and teaching, and finally the model of school-police joint education community.

At the beginning of the project, in most cases, the policemen are allowed to receive students' visits to the public security organs according to requirements from schools. The policemen have an introduction to basic tasks, organizational structure and business processes of the public security organs. They teach students relevant laws and regulations and provide with universal educations such as legal civilization and safety warnings. For example, anti-drug publicity lectures are regularly held, which makes juvenile understand the hazards of drugs by showing the real substance of the drug and describing drug cases, so that juvenile and children will resist drugs from the bottom of their hearts. It is necessary to protect children from drugs, maintaining stability of society.

With the progress of the project, the cooperation between police and school teachers is focusing on purposefully developing experiential and practical education projects and related courses, and begins to carry out the construction of teaching materials and the study on teaching methods. Policemen are also sent into the classroom for safety prevention education, or are appointed to guide students to organize activities such as summer camps, safety publicity and so on. After students' learning, the police have a preliminary effect assessment on students, to fulfill the process of a complete educational activity, which is the formation the alliance model of extramural curriculum and teaching.

On this basis, the project has developed a new model of school-police joint education community. Except the grass-roots public security organs actively serve schools to participate in educational About the Author: Langzi Chen (1982-), male, lecturer at the School of Management, Nanjing Forest Police College; Master of Arts, Criminal Justice, University of Maryland; visiting scholar, University of Baltimore. Research interests include criminal justice, public security management and innovation management. 
activities, the cohesiveness and demonstration effect of young students are also adopted to carry out preventive policing activities, which is the core of this model. For example, during the G20 Summit in August 2016 in Hangzhou, under the leadership of the police, the Little Police trainees in the Children's Sunshine Holiday House together with the safety volunteers went on night patrols on streets, making their own contributions to maintaining community security.

\subsection{Outward union and inward development with enterprises}

With the development of the market economy, enterprises continue to grow up and hold abundant market resources. We regard all enterprise as a Rational Economic Man, his goal is to pursue profit and achieve profit maximization. Nowadays, the competition between enterprises is not limited to the economic field. but it requires enterprises to establish a good corporate image and create a harmonious corporate culture. For enterprises, participating in social public welfare is a good strategy for building a corporate image. At the same time, the state has issued corresponding policies that enterprises can enjoy tax benefits and honorary rewards [9]. At the beginning of the project, there was no sufficient funds, and the organizer was eager to find opportunities to cooperate with enterprises. The enterprise provided project with funds, and the project organizer carried out activities to provide social services, but the results were not optimistic. However, the approach of Develop Public Welfare on the Cultural Basis lacks the continuity of development and cannot be consistent with the purpose and spiritual connotation of the project itself. Therefore, the project gradually adopts the Inward Development model, and strengthens its internal construction, and relies on the Luoshizhuang New Resident Party Branch which is rated as National Outstanding Basic Party Organization, so as to standardize various systems and carry out public welfare activities that meet the needs of service objects. At the same time, the project keeps an open attitude towards learning advanced external organizational development models which can be learned for practice. In the process, it promotes the organization's philosophy of public welfare and expands its influence. It has attracted some companies to actively cooperate with the association based on their common cognition.

As a result, the Children's Sunshine Holiday House project and multiple subjects have initially formed a cooperation pattern of Promotion from Government, Mobilization form College and University, Collaboration with Primary and Junior school, Support from Enterpriser, Participation of Public. It crosses action boundaries of different subjects, and integrates these service resources of diversification, decentralization and dispersion. The basic cooperation model is shown in the figure below. 


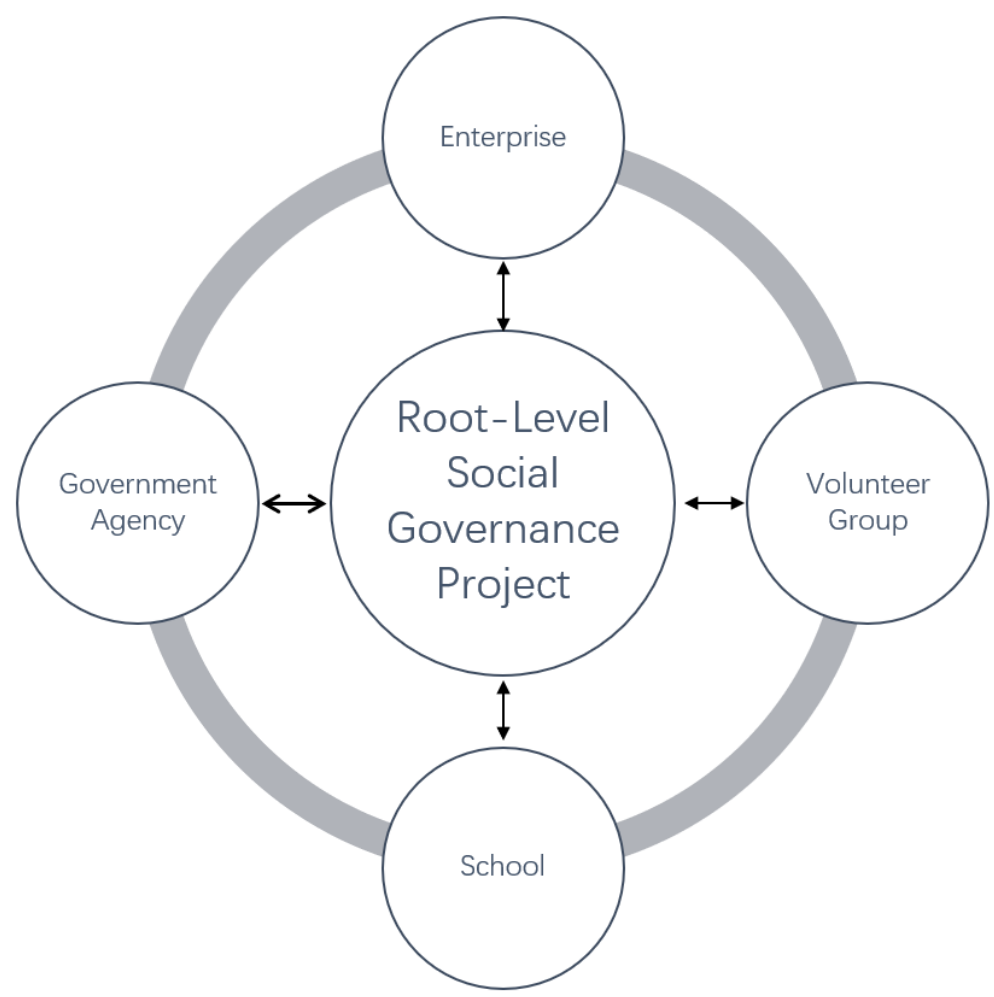

The collaboration among those multiple subjects is a process following the principle of gradual improvement and making the best use of the situation. It is necessary for each subject to break through discrimination among different subjects of different fields and industries. They should insist on an open attitude to form a cooperative state of Mutual Building and Mutual Sharing and Coordinated Development, to establish a long-term cooperation mechanism among multiple subjects.

\section{Experience of Multi-subjects Collaboration of Project}

In consideration of the realistic development in China, attentions and corresponding policies to youth education projects participated by policemen are generally deficient in public security organs. Enterprises don't attach much importance to social goals and ignore some social responsibilities in the development of society. The society is confronted with crisis of public values and dilemma of limited public participation, fragmentation among different industries and diversification of social interests. Meanwhile, there are lacking of attentions and recognitions to projects of same type in the whole society [10], and there also is distrust from society making it difficult for organizations to obtain legality. Facing social environment with limited resources and distrust from society, the Children's Sunshine Holiday House project excavate its own potential, and enhances its capabilities in public welfare service, and explores practical strategies for cross-border cooperation with multiple subjects. The experience of this project provides important lessons for similar projects.

\subsection{Persevering in Value Concept and Pursuing Multi-Fields Cooperation}

The cooperation between grass-roots public security organs and other subjects can be successfully achieved, which depends on common identification to the concept and purpose of project. The values and goals are the foundation of progress and development of project. The cooperation between grassroots public security organs and other subjects in different fields is based on the adherence to organizational values. In the early stage of the project, some insurance companies and sales companies hoped that their advertisements could be implanted in the process of the project, or even About the Author: Langzi Chen (1982-), male, lecturer at the School of Management, Nanjing Forest Police College; Master of Arts, Criminal Justice, University of Maryland; visiting scholar, University of Baltimore. Research interests include criminal justice, public security management and innovation management. 
hoped that the security organs could directly serve their marketing activities. However, all those requirements were rejected by the project leader Mr. Changlin Ma. At the same time, those who truly care about children's development, community safety and public welfare, regardless of size of the enterprises or the individual units, can make equal contributions, and all participants can be equally. The project integrates various social resources and makes use of them, which broadens the scope of resource acquisition and reduces the dependence on a single resource from governments.

\subsection{Enhancing capability of project management to achieve preliminary professional operation}

The key for multi-subjects' joint participation in project is that the project must have strong development strength, which can enhance its attration and absorption ability to external subjects. The core is to enhance the ability of project management to realize professionalization of project operation. The project has established a preliminary financial system, a volunteer management system and an employment system, which can be regarded as the preliminary shape of a standardized social service project. For resources in different types from multiple fields, the project adopts the dealing method of Doing Addition, which integrates service needs of multiple subjects and helps to achieves the goals of each subject at the same time. The realization of these service goals is based on the strong development capacity of the organization. In addition, social supervision methods like publicity are adopted, which initially facilities the professional and standardized development of projects on the whole.

\subsection{Adjusting adaptability of development strategy to promote radiation of cooperation resources}

There are continuous improvements in government's policies and regulations. The changes in situation of market development are on the way. The atmosphere of public welfare in the society is being properly adjusted. Meanwhile, the development status of the project is also changing. The resource dependence theory emphasizes the active responses of organization to the environment [11]. If the project expects to achieve exchanges and dialogues with external subjects and environment, it should dare to face challenges and adjust the strategy by judging the hour and sizing up the situation, instead of carrying out its idea irrespective of external circumstances.

\section{Conclusion}

In conclusion, the grass-roots public security organs should adhere to their own goals of pursuing value, and grasp Preferences of their partners, and expands functional boundaries among different subjects, and integrates multiple development resources in the society during the process of juvenile education and service projects guided by grass-roots public security organs, so as to break through the resource dilemma. Finally, the cross-border cooperation of Complementation and Interconnection and Collaboration and Interaction is achieved among subjects with different resource advantages. In initial building stage of the Children's Sunshine Holiday House project, it has experienced a period of self-denial and mortification. It has initially formed a cooperation pattern of Promotion from Government, Mobilization form College and University, Collaboration with Primary and Junior school, Support from Enterprise, Participation of Public. It is a great exploration for the development of grass-roots governance models led by public security organs. In the process, professionalization and standardization of the project are continuously improved, which is the important principle to be followed; and it is also considerable to absorb superior resources in the external environment, so as to meet a promising future of grass-roots social governance. 


\section{Fund Project}

The paper is a part of achievements of the project A quantitative study on the effectiveness of police youth service project based on structural equation model (2018SJA0597) that guides Universities' Philosophy and Social Science Researches in Jiangsu Province, and the project Research on the management mechanism of police youth service project under the new social governance pattern of mutual construction, governance and sharing(RWZD201802) that guides Fundamental Research Funds for the Central Universities.

\section{References}

[1] Jinwen Xia. Exploration on Modernization of National Governance System and Governance Capability in China [N]. Guangming Daily. 2019-11-19 (06)

[2] Xueqin Min. Drive of Think tank: Exploration on Innovation of Social Governance in China [J]. Social Sciences in Nanjing, 2016 (2): 16-22.

[3] The Handbook of Juvenile Delinquency and Juvenile Justice[M]. Marvin D. Krohn, Jodi Lane (Eds.) Translated by Mingyue Su and langzi Chen. Law Press· China . 2019: 264-266

[4] Robert A. Murphy, Robert A. Rosenheck, Steven J. Berkowitz,. Acute Service Delivery in a Police-Mental Health Program for Children Exposed to Violence and Trauma[J]. Psychiatr Q, 76(2):107-121.

[5] Skorek, Rebecca R., and Christine Devitt Westley. 2016. Evaluation of Chicago Police Department's Crisis Intervention Team for Youth (CIT-Y) Training Curriculum: Year 2[J]. Chicago, Ill.: Illinois Criminal Justice Information Authority.

[6] Yueqin Cui, Yan Sha. Strategy Selection of Seeking Cross-Border Cooperation among MultiSubjects: A Case Study Based on Grass-roots Organizations Breaking Through the Resource Dilemma [J]. Shandong Social Sciences, 2019 (6): 50-55.

[7] Ying Wang. Study on the Sustainable Development of Social Organizations from the Perspective of Urban Governance [J]. Urban Studies, 2019 (5).

[8] Ming Hong. Study on the Basic Model of Cooperative Education between School and Society [J]. China Youth Study, 2016 (1): 97-101.

[9] Wenhuan Yang. Viability and Comparative Advantage: Based on An Analysis Framework of Sustainable Innovation in Grass-roots Governance [J]. Inner Mongolia social sciences, 2019, 40 (3).

[10] Jinhe Zhang, Wenjia Zhuang. Informal Politics:A Action Strategy of Grassroots NGO Taking Example of Case in Preparatory Committee of the Guangzhou Owners' Committee Fellowship [J]. Sociological Study, 2008 (02): 137-154 + 249 .

[11]Sibin Wang. Theoretical Analysis of Urban Community Construction under the System Reform [J]. Journal of Peking University(Philosophy and Social Sciences) (05): 5-14. 